\title{
Surgicel Mimicking Brain Abscess: A Case Report
}

\author{
Ali Niyaf ${ }^{1}$, Kiran Niraula ${ }^{1}$, Chandra Prakash Limbu ${ }^{2}$, Arusha Ali Rasheed ${ }^{1}$, Aminath Zauma ${ }^{1}$ \\ ${ }^{1}$ Department of Neurosurgery, ADK Hospital, Male, Maldives \\ ${ }^{2}$ Department of Neurosurgery, Birtacity Hospital, Jhapa, Nepal \\ Correspondence: \\ Dr. Kiran Niraula \\ Consultant Neurosurgeon, ADK Hospital, Male, Maldives \\ Email: nirkiran@yahoo.com \\ Phone: +977-9849032329
}

\begin{abstract}
Hemostasis is one of the most essential measures in Neurological procedures. Surgicel (Oxidized cellulose) is one of the most frequently used hemostatic agent used worldwide during surgical procedures. We aim to present a case of radiological diagnostic dilemma of a ring enhancing brain lesion where brain abscess, intracranial hematoma and surgicelloma was identified as challenging differential diagnosis. In this paper, we present a case, where a complication occurred with the use of surgicel following craniectomy and evacuation of hematoma.
\end{abstract}

Key Words: Brain abscess, Different diagnosis, Hematoma, Surgicel (oxidized regenerated cellulose)

$\mathrm{O}$ xidized cellulose is a hemostatic agent used during surgical procedures, when regular methods such as ligature and diathermocoagulation are ineffective to achieve. ${ }^{1,2}$ The materials are often left in the surgical bed as they are bio-absorbable. ${ }^{3}$ Oxidized cellulose is left in situ and starts absorption after 24-48 hours, and at the day 7 gauge is surrounded by inflammatory granulation tissue and complete degradation occurs from 4-8 weeks. $^{4}$ However, retained cellulose (surgicel) may mimic abscesses or recurrent tumors.

\section{Case Description:}

36-year-old Right-handed male patient with coexistent diabetes and hypertension presented with history of loss of consciousness left sided hemiplegia and seizures. On examination he was febrile with elevated Blood Pressure of 228/161 mmhg and raised pulse of $169 \mathrm{bpm}$. On general examination patient was conscious and restless with GCS (E3 M5 V1) 9/15. On neurological examination he had left hemiplegia and positive left Babinski sign.
CT brain revealed hemorrhage in the right gangliocapsular region with frontal cortical extension causing mass effect, hence diagnosed as basal ganglia bleed. For which he was operated with right fronto-parieto-temporal craniotomy and evacuation of hematoma. Following day his CT showed residual gangliocapsular hematoma of $5.2 \times 2.0 \mathrm{~cm}$ extending into corona radiata with moderated perifocal edema and mild transcranial herniation of the cerebral parenchyma which shows hemorrhagic contusion. Routine CT prior to cranioplasty to rule out compensated ventriculomegaly and edema. CT films and report were consistent with brain abscess (Figure 1). Patient underwent emergency re-exploration for brain abscess and evacuation. However unexpectedly explored cavity revealed retained surgicel with peri-mass fluid collection - non purulent. Culture was negative for bacterial growth. Hence, the case was diagnosed and treated as Surgicelloma. 


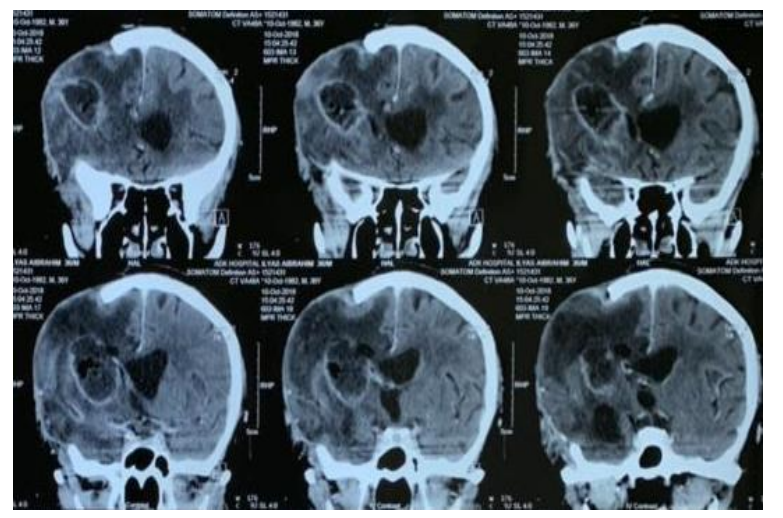

Figure 1: coronal contrast CT image showing Sugiceloma mimicking a brain abscess

\section{Discussion}

Oxidized cellulose (Surgicel) is made of cellulose which is a homopolysaccharide of glucopyranose polymarised through beta-glucosidic bonds. ${ }^{5}$ It provides hostile acidic environment for bacteria. The knit structure of the gauge has bactericidal properties and also is effective against antibiotic resistance microorganisms. ${ }^{6}$ Oxidized cellulose (Surgicel) is re-absorbable material that can be left in surgical site. ${ }^{7}$ Absorption of surgicel starts after 1 to 2 days and complete reabsorption between 4 to 8 weeks. $^{8}$

Absorption is not always complete with retention of surgicel. It is a rare complication for surgicel to appear as mass lesion during the post operating period, mimicking postoperative abscess, bleed or neoplasm. ${ }^{9}$

On MRI, it may reveal nonspecific circumscribed, streaky enhancement in the resection cavity that was suggestive of recurrent disease. ${ }^{4}$ On CT, Surgicelloma may appear as mixed or low attenuation mass containing focal central collection of fluid located inside or near operative site with enhancement at the mass periphery. ${ }^{9}$

Although we are discussing about surgicelloma in the brain, it could also occur after other surgical procedures including laparotomy, laparoscopic cholecystectomy, spinal surgeries, lobectomy, oophorectomy, pneumonectomy, aortic root replacement, hysterectomy, salpingectomy and, nephrectomy. Clinically, prior to surgery, patient may present with fever to paraplegia, cauda equine syndrome, and vision impairment. Differential egneuro Volume 03, Issue 01, 2021 diagnosis can be abscess, cord compression, granuloma, hematoma, non-specified lesion, kidney tumor, Ovarian cancer, heterogonous mass, extradural mass, and tumor recurrence. ${ }^{1,3,5-8,9}$

In this particular case of intracerebral surgicelloma showed raised CRP and ESR without leukocytosis contrary to brain abscess, which usually present with feature of septic foci. Therefore, high index of suspicion is required when dealing with post op ring enhancing lesions.

\section{Conclusion:}

Retained Surgicel can mimic an abscess on imaging. Surgicelloma should be considered as differential diagnosis of ring enhancing lesion in post-operative cases if surgical was used intraoperatively.

\section{References:}

1. Hao Wang and Ping Chen. https://www.ncbi.nlm.nih.gov/pmc/articles/PMC3678855/ ; 1-3

2. Patil DT, Rubin BP. Gastrointestinal stromal tumor: advances in diagnosis and management. Arch Pathol Lab Med. 2011; 135:1298-1310.

3. Guglielmo Niccolò Piozzi, Elisa Reitano, Valerio Panizzo, Barbara Rubino, Davide Bona, Domenico Tringali, Giancarlo Micheletto https://www.amjcaserep.com/abstract/index/idArt/910060 ;1-4, 8-9

4. Kothbauer KF1, Jallo GI, Siffert J, Jimenez E, Allen JC, Epstein FJ. https://www.ncbi.nlm.nih.gov/ pubmed/11565875; $1-9$

5. Oto A, Remer EM, O'Malley CM et al: MR characteristics of oxidized cellulose (Surgicel). Am J Roentgenol, 1999

6. Sandhu GS, Elexpuru-Camiruaga JA, Buckley S: Oxidized cellulose (Surgicel) granulomata mimicking tumour recurrence. Br J Neurosurg, 1996

7. Mausner EV, Yitta S, Slywotzky CM, Bennett GL: Commonly encountered foreign bodies and devices in the female pelvis: MDCT appearances. Am J Roentgenol, 2011

8. Young ST, Paulson EK, McCann RL, Baker ME. Appearance of oxidized cellulose (Surgicel) on postoperative CT scans: Similarity to postoperative abscess. AJR Am J Roentgenol. 1993; 160:275-277. doi: 10.2214/ajr.160.2.8424333

9. Young ST, Paulson EK, McCann RL, Baker ME. Appearance of oxidized cellulose (Surgicel) on postoperative CT scans: Similarity to postoperative abscess 